\title{
Effect of gallbladder 21 (GB21) acupressure on length of delivery in nulliparous women
}

Hamideh Torkiyan ${ }^{1}$, Sedigheh Sedigh Mobarakabadi ${ }^{2 *}$, Alireza khajavi ${ }^{3}$, Reza Heshmat ${ }^{4}$, Samad Safiloo $^{5}$, Giti Ozgoli ${ }^{6}$

1. MSc Student in Midwifery, Students Research Committee, Department of Midwifery and Reproductive Health, School of Nursing and Midwifery, Shahid Beheshti University of Medical Sciences, Tehran, Iran. ORCID ID: 0000-0002-4677-033x

2. Assistant Professor, Midwifery and Reproductive Health Research Center, Department of Midwifery and Reproductive Health, School of Nursing and Midwifery, Shahid Beheshti University of Medical Sciences, Tehran, Iran. ORCID ID:0000-0002-7330-1037

3. Ph.D student of Biostatistics, Departments of Biostatistics, Faculty of Paramedical Sciences, Shahid Beheshti University of Medical Sciences, Tehran, Iran. ORCID ID:.0000-0001-5238-792x

4. MD, Acupuncturist \& Osteopath, Iranian Scientific Acupuncture Association, Tehran, Iran. ORCID ID:0000-0001-75303530

5. MSc student of Biostatistics, Faculty of Paramedical Sciences, Shahid Beheshti University of Medical Sciences, Tehran, Iran. ORCID ID: 0000-0003-4124-3626

6. Associate Professor, Midwifery and Reproductive Health Research Center, Department of Midwifery and Reproductive Health, School of Nursing and Midwifery, Shahid Beheshti University of Medical Sciences, Tehran, Iran., (Corresponding Author), Tel: 02188202012, Email: gozgoli@gmail.com, ORCID ID: 0000-0003-2111-7024

\section{ABSTRACT}

Background and Aim: Length of delivery is among the factors affecting maternal and neonatal delivery outcomes. The effect of acupressure on decreasing the length of delivery stages has been recently evaluated. The aim of this study was to assess the effect of acupressure on gallbladder (GB21) acupoints on the duration of delivery.

Materials and Methods: This clinical trial included 174 nulliparous women hospitalized in Mofateh Maternity Hospital in Varamin City who were eligible to enter the study. The women were randomly placed into three groups: pressure on GB21, pressure on inappropriate point (sham) and control groups. Intervention was applied during 3 stages: at $3-5 \mathrm{~cm}, 6-7 \mathrm{~cm}$, and $8-10 \mathrm{~cm}$ dilatations at the first stage of labor and the lengths of delivery stages were measured. Data were analyzed using one-way ANOVA, Kruskal Wallis, Tukey, Bonfferoni and chi-square.

Results: Mean values for duration of the first stage of delivery in GB21, sham and control groups were $257.67 \pm 72.86,289.31 \pm 118.72$, and $245.09 \pm 80.82 \mathrm{~min}(\mathrm{P}<0.05)$ and for the lengths of the second stage of labor were $71.98 \pm 39.89,64.31 \pm 22.91$ and $71.50 \pm 32.02 \mathrm{~min}$ respectively $(\mathrm{P}>0.05)$. Mean values for the lengths of the third stage in the GB21, sham and control groups were $5.17 \pm 0.9,5.43 \pm 1.4$, and $6.29 \pm 2.2$ min respectively $(\mathrm{P}>0.05)$. There was no significant differences among the 3 groups in regard to Apgar Scores $(p<0.05)$. But the required dose of oxytocin and the mean value for the duration of oxytocin administration were higher in the sham and control groups than that in the GB21 acupressure group $(\mathrm{P}<0.003)$.

Conclusion: No statistically significant difference was found in the duration of labor in the three groups, but the required dose and duration of oxytocin administration in the acupressure group were much less in the GB21 acupressure group than in the other two groups.

Keywords: Acupressure, Gallbladder 21, Inappropriate point, Nulliparous women, Childbirth Received:_Sep_6,2019 Accepted: Jan 19, 2020

How to cite the article: Hamideh Torkiyan, Sedigheh Sedigh Mobarakabadi, Alireza khajavi, Reza Heshmat, Samad Safiloo, Giti Ozgoli. Effect of gallbladder 21 (GB21) acupressure on length of delivery in nulliparous women.SJKU 2020;25(4):56-69.

Copyright (C) 2018 the Author (s). Published by Kurdistan University of Medical Sciences. This is an open access article distributed under the terms of the Creative Commons Attribution-Non Commercial License 4.0 (CCBYNC), where it is permissible to download, share, remix, transform, and buildup the work provided it is properly cited. The work cannot be used commercially without permission from the journal 


\title{
بررسى تأثير طب فشارى نقاط كيسه صفراوى اY بر طول مدت زايمان زنان نخست زا
}

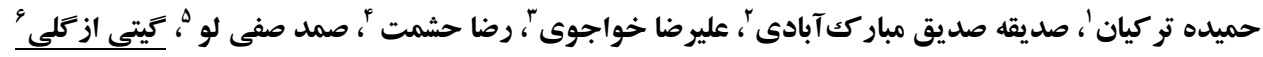

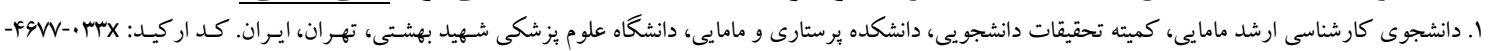

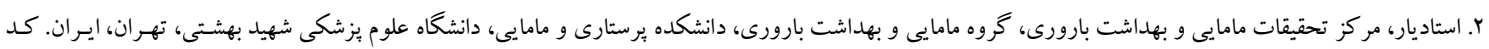 \\ اركيد:

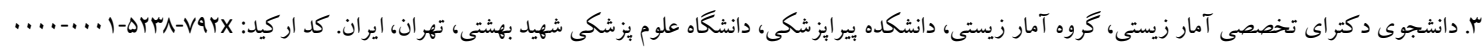

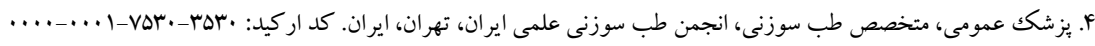

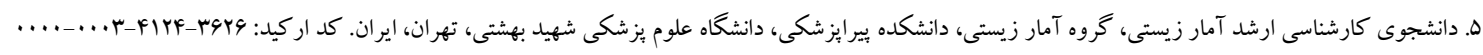

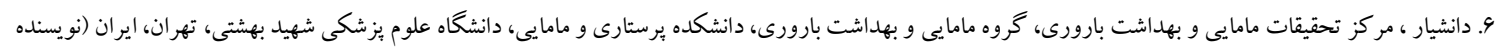

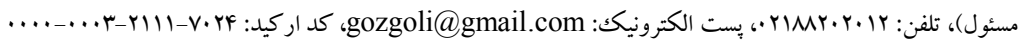

جָكيله

زمينه و هدف: طول مدت زايمان از عوامل مؤثر بر بيامدهاى مادرى و نوزادى زايمان است. از روشهاى در دست تحقيق، بررسى تأثير طب فشارى بر كاهش طول مدت مراحل زايمانى است. هدف اين مطالعه بررسى تأثير طب فشارى نقاط كيسه صفراوى الب بر طول مدت زايمان زنان نخست زا است.

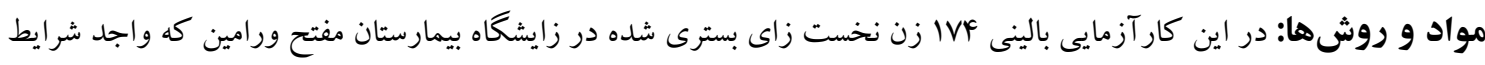

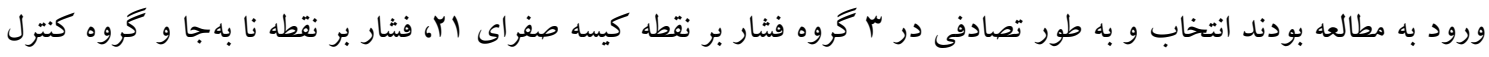

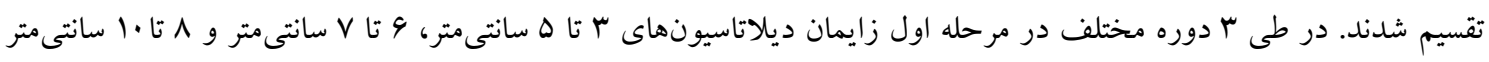

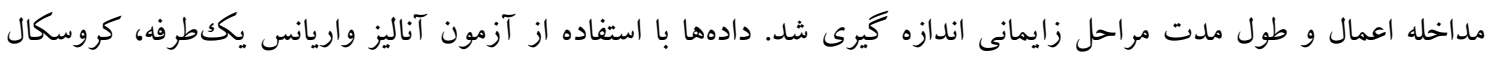
واليس، توكى، بن فرونى، مجذور كا، آناليز شد.

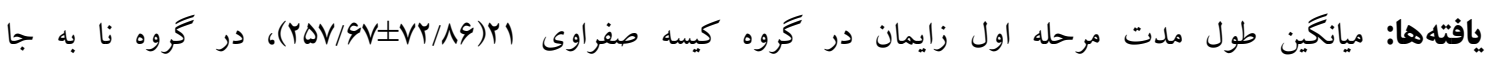

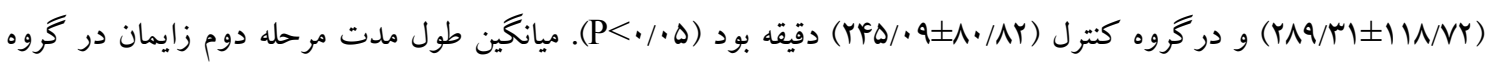
كيسه صفراوى الr(Y)

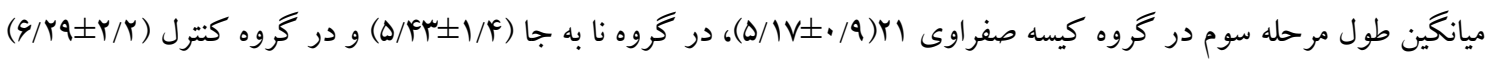

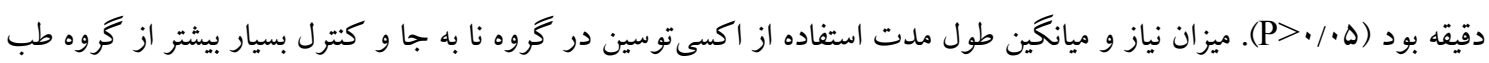

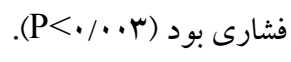

نتيجه كيرى: با اينكه تفاوت آمارى معنىدارى در سه گروه به لحاظ طول مدت مراحل زايمان مشاهده نشد؛ اما ميزان نياز به

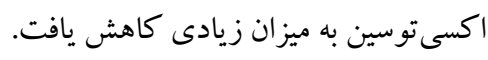

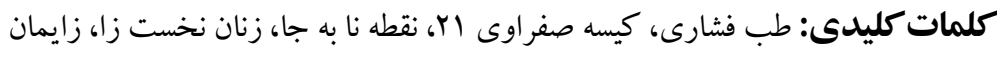

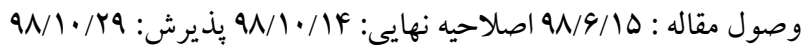


صناعى است(1). اين دارو در كنار تقويت انقباضات رحمى با عوارض جانبى همجون خشكى دهان، برافروختكى صورت، فوتوفوييا، بى اختيارى ادرار، احتباس ادرارى، يبوست(V)، تهوع، تشديد انقباضات رحمى، آريتمى قلبى، كاهش درجه حرارت بدن، كاهش يون سديم خون و مسموميت با آب، اسباسم و باركى رحم، تشديد انقباضات

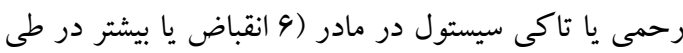
ا ادقيقه) و كاهش ضربان قلب جنين و كاهش نمره آبشار

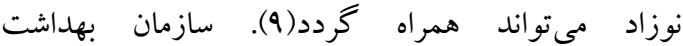
جهانى(WHO) گزارش مىدهد كه مادران و نوزادان زمانى از مزاياى زايمان طبيعى بهره خو اهند برد كه مداخلات كم ترى براى آنها در طى ليبر انجام شود و زنان از بالاترين

ميزان حمايت روحى و روانى برخوردار باشند( •(1). از جمله روشهاى در دست بررسى در جهت كاهش طول

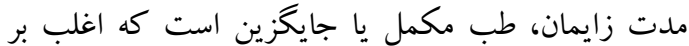

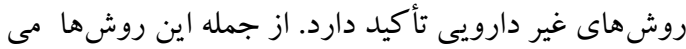

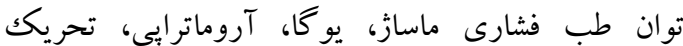
الكتريكى از راه بوست، تغيير وضعيت، كار برد سرما و

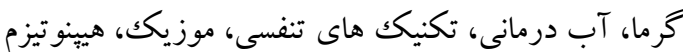

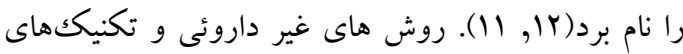
غير تهاجمى روشهايى آسان، ارزان و مؤثر در كاهش طول

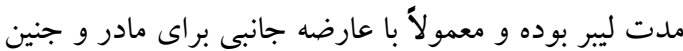

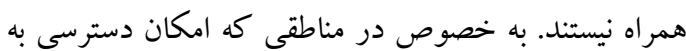
روشهاى داروئى در كاهش طول مدت ليبر وجود ندارد،

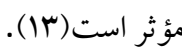

يكى از روشهاى غير دارويى و غيرتهاجمى مؤثر بر طول

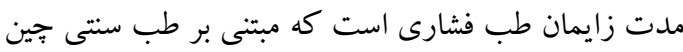

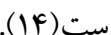

بر طبق طب سنتى حين، انرزى حياتى به نام كى (Chi)،

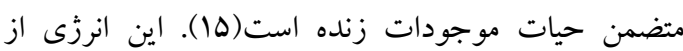
طريق مريدين ها يا كانالهاى انرزى در سرتاسر بدن جندات جريان مىيابد. در بدن دوازده مريدين اصلى وجود دارد. طب لهب

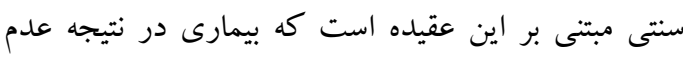

مقدمه

زايمان فرآيندى است كه با آغاز انقباضات منظم آغاز مى گردد و با افزايش شدت و تواتر انقباضات تداوم مىيابد(1). اين امر با باز شدن تدريجى دهانه رحم (dilatation) خروج جنين همراه است(ז, (1). ميانگين طول مدت مرحله ول زايمان كه متشكل از دو فاز نهفته و فعال است در افراد مختلف متفاوت است. در اين ميان سنجش طول مدت فاز نهفته زايمان دشوارتر بوده و ملاكك در بسيارى از بررسىها زمان مراجعه مادر به بيمارستان است. مدت زمان تقريبى آن

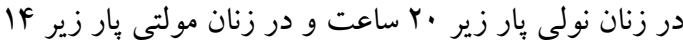
ساعت عنوان شده است. ميانگين طول مدت مرحله فعال

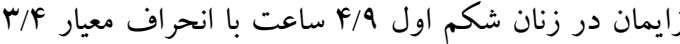
ساعت مطرح گرديده است(1). از جمله عواملى كه مىتواند موجب طولانى تر شدن اين مدت گردد مىتوان به وضعيت

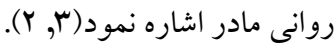
ترس و اضطراب مادر با افزايش كاتكول آمينها يا هورمونهاى استرس همراه است. اين افزايش از طريق بازخورد منفى بر غده هييوفيز به كاهش ترشح هورمون

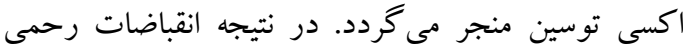
كاهش يافته و حتى در مواردى قطع مى گرد دد. به دنبال اين فرآيند روند زايمان طولانى و حتى ممكن است متوقف كردد(ץ, Y). اين مسئله موجب انجام مداخلات متعددى مى گردد كه مىتواند عوارض زيادى را با خود به همراه داشته باشد و از طرفى ديخر مىتواند براى مادر و بيمارستان يرهزينه باشد(ه). از جمله اين عوارض مى توان به افزايش ميزان زايمان سزارين، زايمان با ابزار، خونريزى و عفونت بعد زايمان در مادر (9) و تحت فشار قرار گرفتن سر، اختلال در اكسيزن رسانى جنينى، كاهش pH خون شريانى، نمره آيخار بايين و بروز مر گك و مير در نوزادان اشاره نمود(^ر,

رويكرد مرسوم در درمان تقويت انقباضات رحمى و مقابله با هييوتونى رحم، رويكرد طبى يعنى كاربرد اكسى توسين 
و مؤثر در جهت ارتقاء سلامت مادران و كودك وجود دارد. اطلاعات موجود در خصوص اثربخشى تحريك نقاط صفراوى اY بر طول مدت زايمان محدود و غير قابل نتيجه كيرى قطعى است. لذا اين مطالعه با هدف تعيين اثر بخشى طب فشارى نقاط صفراوى الب بر طول مدت فاز فعال زايمان

$$
\text { زنان نخست زاطراحى و اجرا گرديد. }
$$

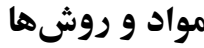

اين مطالعه يكك كار آزمايى بالينى تصادفى يكك سو كور بود كه در زنان نخست زاى مراجعه كننده به بخش زايمان بيمارستان شهيد مفتح ورامين از اسفند ماه سال وهسا تا شهريورماه سال VQTM النجام شد. معيارهاى ورود به مطالعه، .

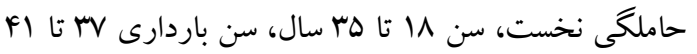
هفته، تكك قلو بودن، داشتن حداقل سواد خواندن و نوشتن، بودن در ابتداى فاز فعال زايمان، عدم موارد شناخته شده اختلالات روانى (سايكوز، اسكيزوفرنى) و آناتومى (ناهنجارىهاى رحمى و تنخى لكن)، عدم ابتلا به بيمارىهاى مزمن (بيمارىهاى قلبى، ريوى، ديابت و فشارخون)، عدم وجود حاملكَىهاى :يرخطر (فشارخون حاملكَ، كاهش حركات جنين، محدوديت رشد داخل رحمى، مرگك جنين، بلى يا اوليكوهيدرآمنيوس، پارگى يردهها بيش از r اساعت)، سابقه نازايى، نمايش سفاليكك سر جنين بود. معيارهاى خروج از مطالعه نياز به زايمان سزارين

$$
\text { اورزانس و عدم تمايل به ادامه شركت در مطالعه بود. }
$$
اين مطالعه در كميته اخلاق دانشخاه علوم يزشكى شهيد

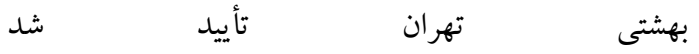

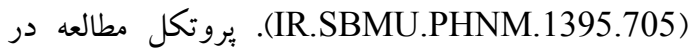

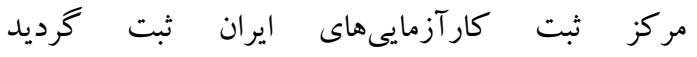

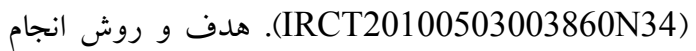
مطالعه و محرمانه باقى ماندن اطلاعات براى تمام مشاركت كنند كان توضيح داده شد و رضايت نامه آكاهانه از تمام

$$
\text { افراد اخذ گرديد. }
$$

تعادل انرزى ايجاد مىشود، براى تصحيح اين عدم تعادل، نقاط خاصى از بدن تحريكك مى گردد. لازم نيست اين نقاط در نزديكى اندام متأثر باشد(19). تحريك نقاط در طب فشارى توسط كف دست، مشت يا نرمه انخشتان اعمال مىشود. طب فشارى را مىتوان در طى باردارى، زايمان و بعد از زايمان به منظور تسكين نار احتى ها به كار برد(IV). از جمله نقاط مؤثر بر انقباضات رحمى، القاى ليبر و طول مدت ليبر SP6,LI6,GB21 وBL60 است. نقاط صفراوى آ بر روى مريدين كيسه صفرا قرار دارد. مكان آناتوميك آن، روى شانه در حد فاصل استخوان آكروميون و مهره هفتم گردنى است(1) (شكل (1). جهت تقويت انقباضات رحمى كه مىتواند با بيشرفت آهسته زايمان همراه باشد مىتوان از تحريكك نقاط صفراوى ال استفاده نمود(19). طب فشارى از طريق تحريكك فيبرهاى عصبى ناز كك موجب انتقال ييام به مغز ميانى، نخاعى و محور هييوفيز مى گردد كه به ترشح اندروفينها منجر مى گردد. بازخورد مثبتى كه اندروفين بر ترشح اكسى توسين دارد مى تواند منجر به افزايش ترشح آن و در نتيجه تحريك و تقويت انقباضات كردد(·) (Y). همجنين اين نقاط در تسريع نزول جنين در فاز فعال و مرحله دوم زايمان مؤثر عنوان شده اند(19 11) يكك كارآزمايى بالينى كه با تحريك نقطه كيسه صفراوى اب به همراه تحريكك ساير نقاط (sp6,li4) انجام و با گروه كنترل مقايسه گرديد، مشخص شد كه تحريك اين نقاط با زايمان وازينال خود به خودى بيشترى همراه بود(Y). در كار آزمايى بالينى ديخرى، تفاوت آمارى معنىدار به لحاظ طول مدت زايمان بين كروه صفراوى الr، نقطه 4 طحالى (SP6) امروزه درمان هاى مكمل و غير دارويى به بخش كسترده و جدايى نايذيرى از زندگى انسان تبديل شده و به طور روز افزونى با علم مامايى عجين گرديده است. اين در حالى است كه تأكيد روزافزونى نيز به رويكردهاى بالينى مبتنى بر شواهد وجود دارد(Y). با توجه به اين امر نياز به كسترش مرزهاى دانش در خصوص روشهاى غير دارويى، كم خطر 


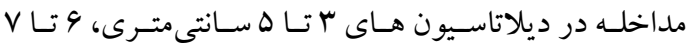
سانتى متـرى و ^ تـا • ا سـانتى متـر انجـام شـد. قبـل از شـروع مداخله انقباضات رحمى بـه مـــت · ا دقيقـه كنتـرل، تـواتر، شدت و طـول مـدت انقباضـات ثبـت كرديـد؛ و توضـيحات لازم در خصوص انقباضات به مادر داده شد. سيس در گروه فشار بر نقطه GB21 از مادر خواسته شد كه در هر وضعيتى كه راحت است قـرار بكيـرد و مامـاى مداخله گَر خـود در روبروى مادر قرار مى گرفـت. از مـادر خواسته مسىشــ كـه

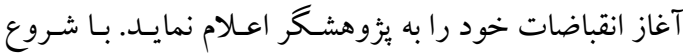
انقباضـات رحمسى و احسـاس درد در مـادر، بـر روى نقطـه مذكور (تصوير () فشار با كمكك انگشتان دست اعمال شـد.

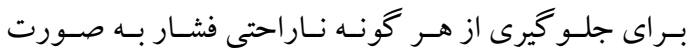
تجرخى و در حدى اعمال شد كه منجر به تغيير رنگك نـاخن محقق شود. در يايان هر انقباض اعمـال فشـار متوقـف شـــ و بـا شـروع انقبـاض بعـدى و احسـاس درد مـادر مجـلدد فشـار

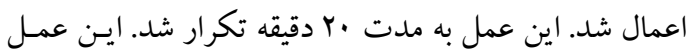

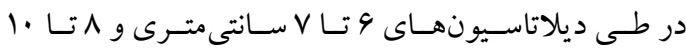
سانتى متر نيز تكرار شد.

تصوير I. مكان آناتوميكك نقطه صفراوى IT

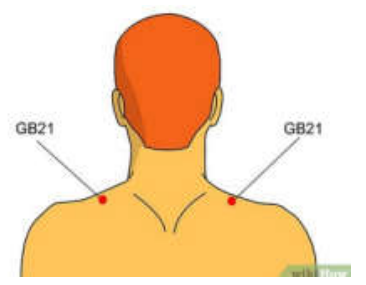

محقق اجرا كننده مداخله، ابتدا تعيين نقطه و روش طب فشارى را نزد متخصص طب سوزنى (مشاوره تخصصى مطالعه) آموخت. سبس جهت تعيين صحت روش انجام طب فشارى، متخصص طب سوزنى و ماماى مداخله گر به اعمال فشار بر نقطه كيسه صفراوى اY روى ده نفر برداختند. به اين ترتيب كه در ينج نفر توسط متخصص فشار به مدت يكك دقيقه بر نقطه كيسه صفراوى راست اعمال و نتايج حاصله از فشار صحيح به نام احساس دكى با استفاده از جكك ليست احساس دكى (احساس درد مبهم، كرختى، انبساط عضلانى، سنگينى، فشار، بى حسى، كرما و احساس آرام شدن كه در اغلب موارد در امتداد كانال منتشر مى گردد) سنجيده شد. سبس ماماى مداخله كر به فاصله زمانى ينج دقيقه بر نقطه كيسه صفراى جִب افراد اعمال فشار كرده و جִك ليست مربوطه را تكميل نمود. در ينج نفر ديخر اين كار به صورت عكس انجام شد. اطلاعات حاصل از بررسى دو ارزياب توسط آزمون مكك نمار و ضريب توافق كايا بررسى شد. آزمون Kappa=1 و نتيجه آزمون مكك نمار با هـ/ نشان دهنده ميزان بالاى توافق بين محقق و متخصص طب سوزنى بود. نتايج نشان دهنده عدم اختلاف در بين ماماى مداخله كر و متخصص بود. زنان نخست زايى كه جهت زايمان در بخش بسترى مىشدند و مشخصات واحد يُزوهش را داشتند به صورت مبتنى بر هدف انتخاب مىشدند، بعد از تكميل فرم رضايت آكَاهانه وارد مطالعه مى شدند سبس با استفاده از نرم افزار طب (Yrandom allocation software فشارى نقاط كيسه صفراى آ، طب فشارى نقاط نا به جا و كنترل) قرار كرفتند (الكوريتم شماره (). حداقل تعداد نمونه

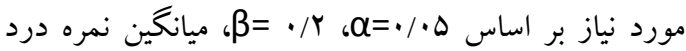
مورد انتظار در گروه شاهد M=ه/V9 ، ميانخين نمره درد

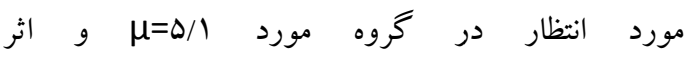
اندازه:هr/

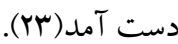


فقط يكك مادر مورد مداخله قرار مى گرفت و تا پايان مرحله سوم زايمان و انتقال مادر به بخش مراقبت بعد از زايمان

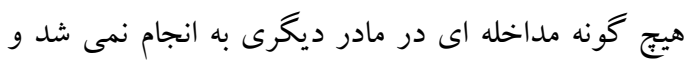

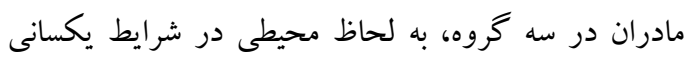
مورد بررسى و مداخله قرار خرفتند. نياز به دريافت اكسىتوسين، زمان و ميزان آن، الخوى مردي انقباضات رحمى و نمره بيشاب، تصميم به انجام زايمان

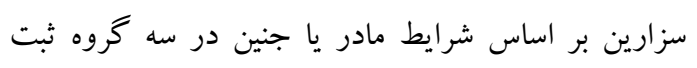

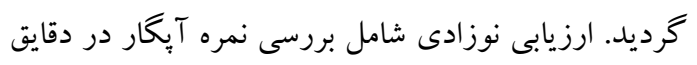

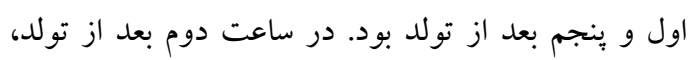
رضايت مادر از مداخلات و نيز تمايل به استفاده مجدد از اين روش مورد بررسى قرار گرفت.

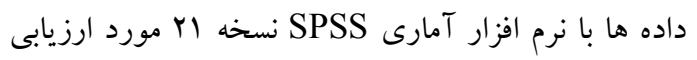

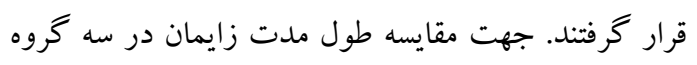

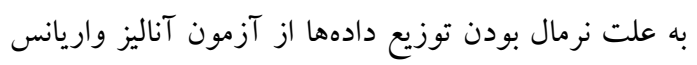

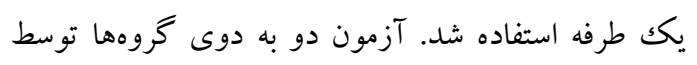
آزمون توكى با تصحيح بن فرونى انجام شد. آزمون

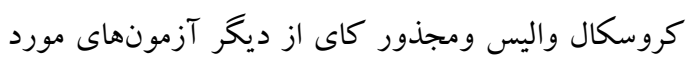

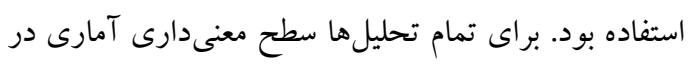
حد هـ/· در نظر گرفته شد.

يافته ها تمامى IVF فرد شركت كننده در اين مطالعه به طور كامل در مطالعه شركت كردند (شكل r).
در گروه طب فشارى نقطه نا به جا، نقطه اي در فاصله يكك

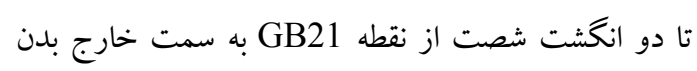
كه در آنجا هيج نقطه سوزنى وجود ندارد، جهت اعمال فشار انتخاب شد. تمامى مراحل و نحوه اعمال فشار مشابه گروه طب فشارى نقاط كيسه صفراوى الب بود. گروه كنترل بدون دريافت هيج گونه فشارى مراقبت هاى روتئن دريافت مى كردند. در همه گروهها (خروه طب فشارى بر نقطه كيسه صفراوى

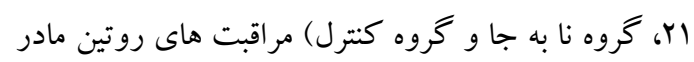

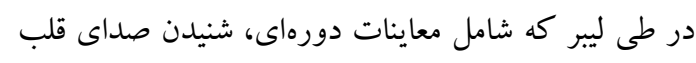

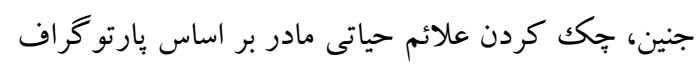

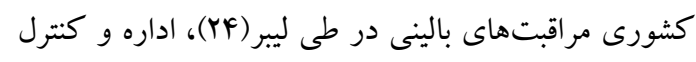

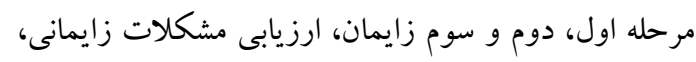

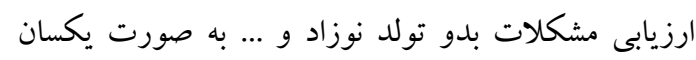
انجام شد. در گروه كنترل، بثزوهشخر تنها در كنار زائو حضور يافت و كليه اقدامات به جز فشار را براى افراد اعمال كرد. در اين

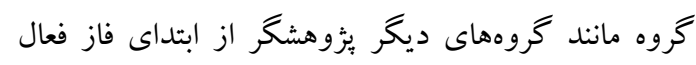

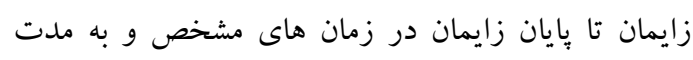

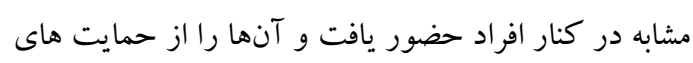

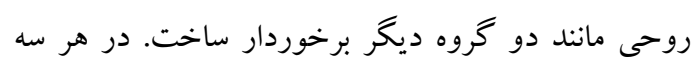

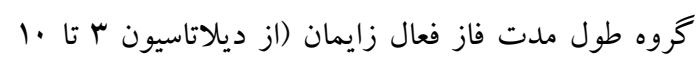

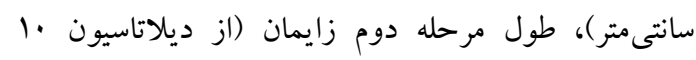

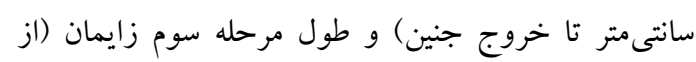

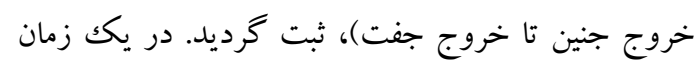




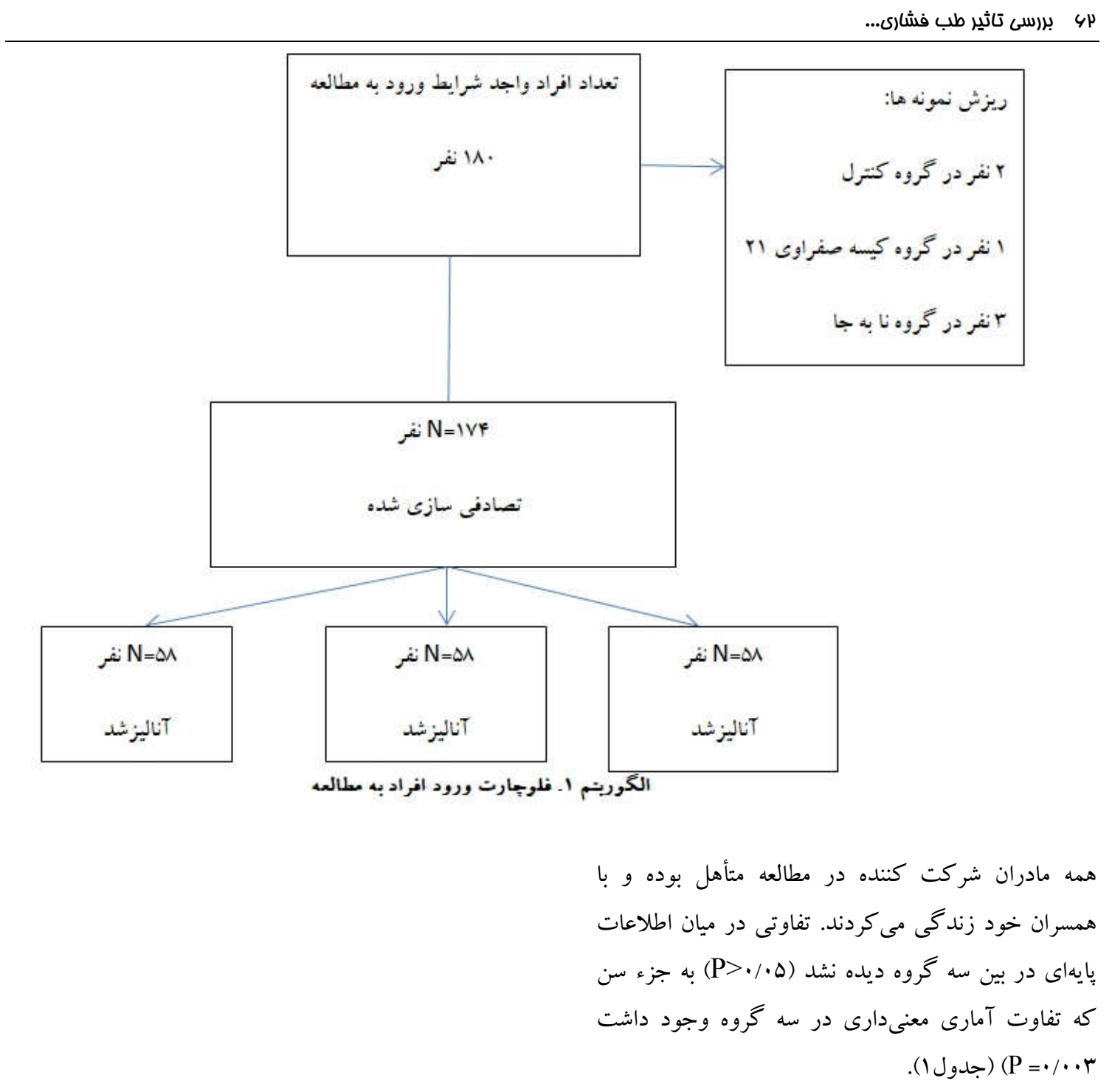


جدول 1. مشخصات يايه در گروههاى مورد مطالعه

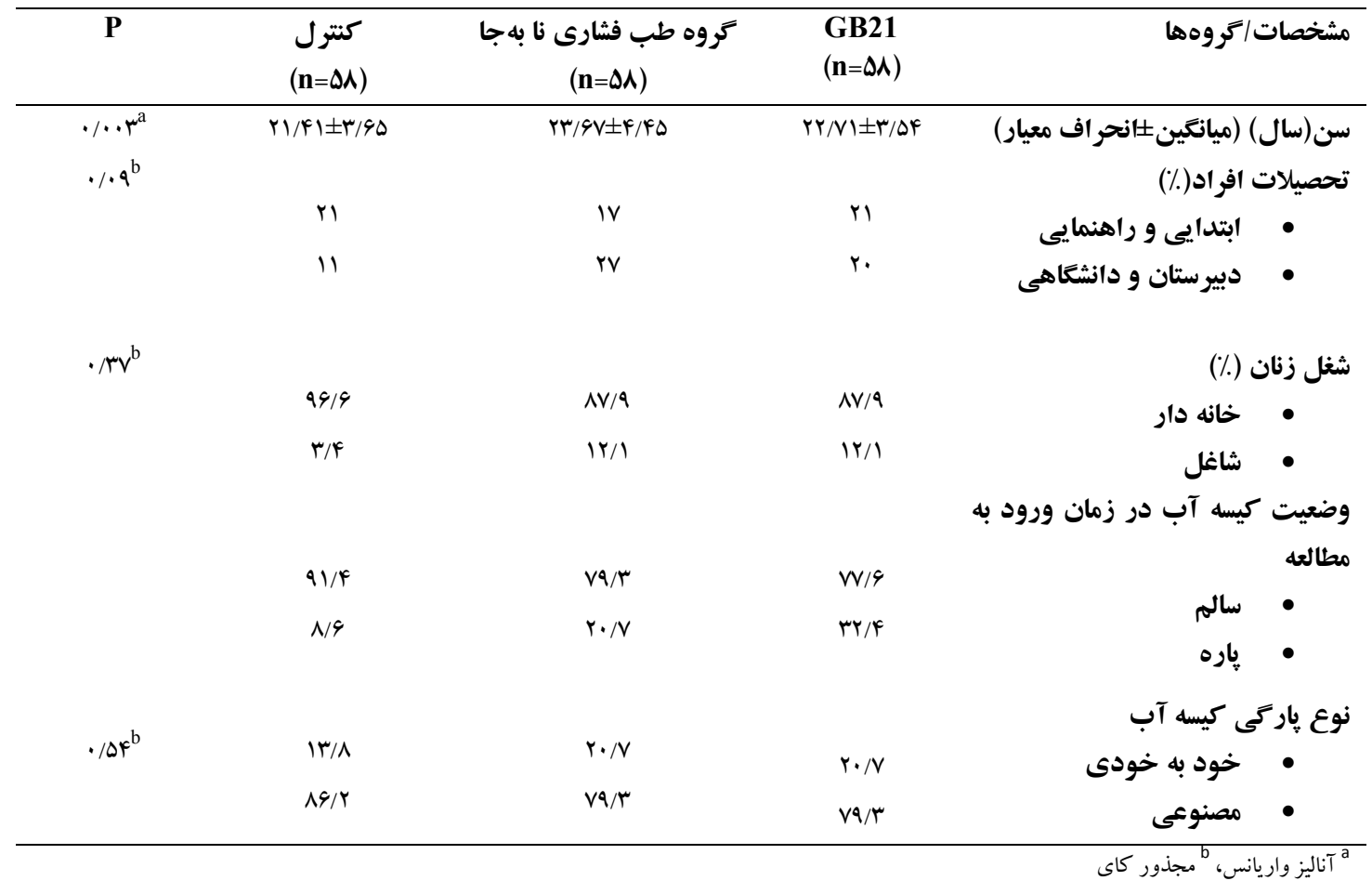

تفاوت آمارى معنىدارى را نشان نداد (ه•/•> P). اين نتايج نشان دهنده اين مطلب بود كه طب فشارى رسارى نقاط كيسه صفراوى Y تأثيرى در كاهش طول مدت مرحله اول زايمان ندارد. نتايج آزمونهاى آمارى نشان داد كه در مرحله دوم و سوم زايمان نيز تفاوت آمارى معنىدارى درى سمايج

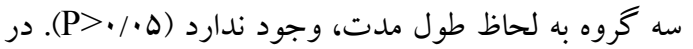

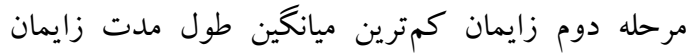

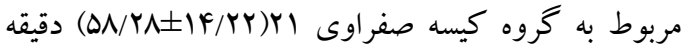
بود (P=•/Tr) كه بيشترين تأثير را در كاهش زمان مرحله دوم زايمان داشت؛ ولى اختلاف معنىدار نبود (جدول Y).
آزمون آناليز واريانس يك طرفه تفاوت آمارى معنىدارى را در سه گروه به لحاظ طول مدت مرحله اول زايمان نشان

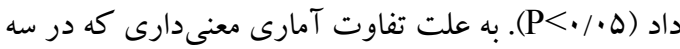
كروه به لحاظ سن مشار كت كند كان وجود داشت، آزمون كوواريانس انجام شد. مشخص شد با حذف اثر اين عامل نيز تفاوت آمارى معنىدارى در سه گروه به لحاظ طول

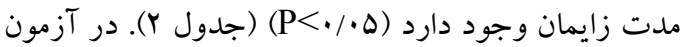
دو به دوى گروه ها كه توسط آزمون توكى با تصحيح بن

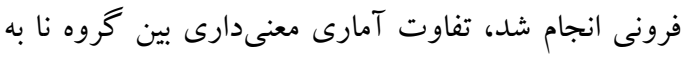
جا و كنترل (ه•/•> P)، مشاهده شد. گروه كيسه صفراوى ابو گروه نا به جاو نيز گروه صفراوى ابو گرروه كنترل 
جدول r. مقايسه طول مدت زايمان در گروههاى مورد مطالعه

\begin{tabular}{|c|c|c|c|c|}
\hline نتيجه آزمون a & انحر اف معيار & ميانكين & كروهoها & فاز زايمان \\
\hline \multirow[t]{3}{*}{$\mathrm{P}=\cdot / \cdot r$} & $V Y / \Lambda$ & $r \Delta V / 9$ & كيسه صفراوى Yl & طول مرحله اول زايمان \\
\hline & $111 / \mathrm{V}$ & $r \wedge Q / r$ & نا به جا & \\
\hline & $\Lambda \cdot / \Lambda$ & $Y F \Delta / \cdot 9$ & كنترل - & \\
\hline \multirow[t]{3}{*}{$\mathrm{P}=\cdot / r \mathrm{r}$} & $r q / \Lambda$ & $V 1 / 9$ & كيسه صفراوى Iا Y & طول مرحله دوم زايمان \\
\hline & $r Y / Q$ & $94 / \pi$ & نا به جا & \\
\hline & $r q / . r$ & $V / \Delta$ & 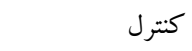 & \\
\hline \multirow[t]{3}{*}{$\mathrm{P}=\cdot / Y F$} & $\cdot / 9$ & $\Delta / I V$ & كيسه صفراوى II & طول مرحله سوم زايمان \\
\hline & $1 / 4$ & $\Delta / 4 \mu$ & نا به جا & \\
\hline & $r / r$ & $9 / 49$ & كنترل & \\
\hline
\end{tabular}

توكى با تصحيح بن فرنى تفاوت آمارى معنىدارى را در

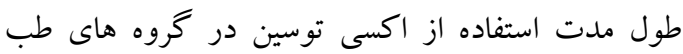

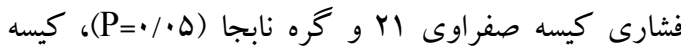

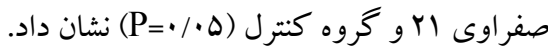
نمره آيگًار در تمام گروه ها در محدوده طبيعى بوده و تفاوتى در بين گرووه ها وجود نداشت (D>-ه). ميزان رضايتمندى بر اساس دو معيار ليكرت در رضايتمندى و تمايل به استفاده مجدد از اين روش بررسى شد. ميان رضايتمندى و تمايل به استفاده مجدد از روش مداخله بين سه گروه تفاوت آمارى معنىدارى وجود داشت و در گرووه كيسه صفراوى ال تمايل بيشترى در استفاده مجدد از اين

$$
\text { روش وجود داشت ( (P> P) (جدول r). }
$$

كروهها از نظر شرايطى همجيون مراقبتهاى دوران باردارى و وضعيت كيسه آب در زمان بسترى شدن تفاوت آمارى معنى جهت يكك نفر از نمونه ها از يتيدين استفاده شد. همجنين در اين مطالعه در گرووه كيسه صفراوى اY (Y نفر)، در گروه نا به جا (س نفر) و در كروه كنترل براى (4 نفر) از مادران از اكسىتوسين در جهت تحريكك دردهاى زايمانى استفاده شد. ميانگين طول مدت استفاده از اكسىتوسين در گروه

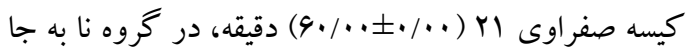

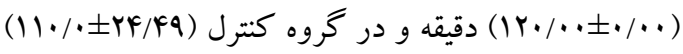
دقيقه بود. آزمون آناليز واريانس يك طرفه تفاوت Tارى

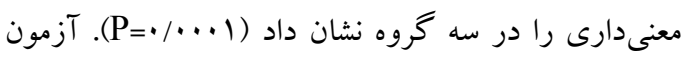

جدول سا. مقايسه بيامد ثانويه متغيرها و رضايت مندى در ميان كروهها

\begin{tabular}{|c|c|c|c|c|}
\hline $\mathbf{P}^{\mathbf{a}}$ & كنترل & نا به جا & Gb21 & ييامد/كروه ها \\
\hline$\cdot / \cdots 1^{a}$ & FA & Fr & $1 \ldots$ & تمايل به استفاده مجدد \\
\hline \multirow[t]{3}{*}{$\cdot 14^{b}$} & & & & نمره آيعار \\
\hline & $\wedge / ৭ \wedge \pm \cdot / 1 \mu$ & $q / \cdots \pm \cdot / \cdot$ & $\wedge / ৭ \wedge \pm \cdot / / \mu$ & • • دقيقه اول \\
\hline & 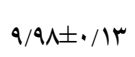 & $1 \cdot / \cdot \pm \cdot / \cdot$ & ৭/৭४ $\pm \cdot / / r$ & دقيقه ينجم \\
\hline
\end{tabular}


IIngram استفاده نمودند كه مىتواند اثرات مختلفى داشته باشند. مطالعه ما نشان داد كه تحريك نقاط كيسه صفراى آب به خودى خود مى تواند طول مدت مرحله اول زايمان را در لهر دامنهاى كمتر از آن خه در مطالعات فوق ذكر شد قرار دهد. آن جه كه موجب شد ما نتوانيم به نتايج معنادارى در سه

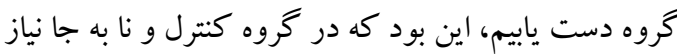

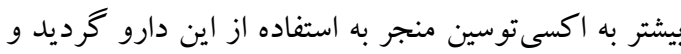
در نتيجه كاربرد آن طول مدت ليبر در گروه كنترل و نابه جا كاهش يافت و منجر شد به اين كه ما به نتايج معنادارى در سه گروه دست بيدا نكنيم. Akbarzadeh| اى نقاط وطحالى و كيسه صفراوى آ و مقايسه آن با كروه كنترل از نظر طول مدت زايمان و نوع زايمان در زنان نخست زا برداختند. در اين بررسى مشخص شد يكك مرحله

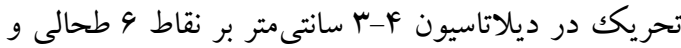
نيز در نقاط كيسه صفراوى I مى تواند در كاهش طول

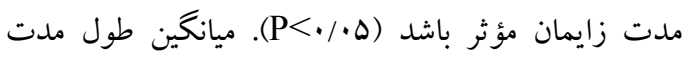
مرحله اول ليبردر گروه كيسه صفراوى الr در اين مطالعه

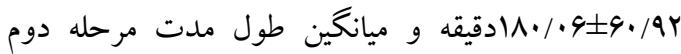

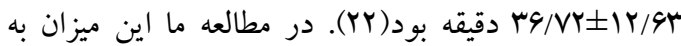
ترتيب IV/A

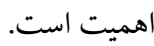
در مطالعه ديخر از Akbarzadeh و همكاران (ها.ب) با هدف مقايسه كاربرد طب فشارى تككمحلهاى در ديلاتاسيون r تا F سانتىمتر نسبت به كاربرد دو مرحله اى

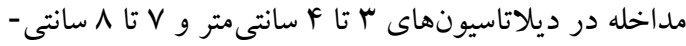
متر بر نقاط كيسه صفر اوى اY انجام شد. در اين مطالعه طول

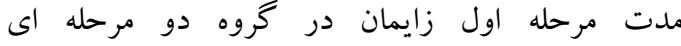

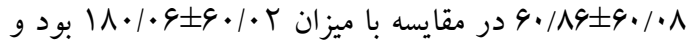
تفاوت آمارى معنىدارى بين دو گروه به لحاظ طول مدت

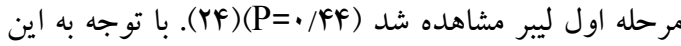

در اين كار آزمايى بالينى تصادفى ما طول مدت سه مرحله

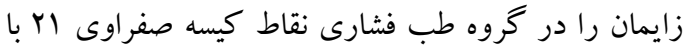

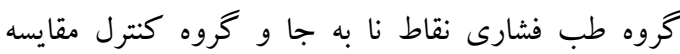

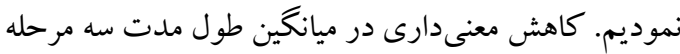

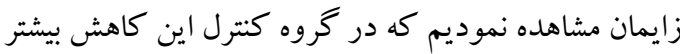

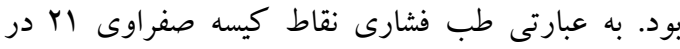
كاهش طول مدت زايمان مؤثر نبود.

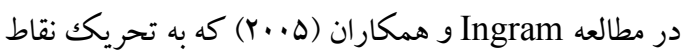
هو گو، كيسه صفراى آ و SP6 در S94 زون باردار و مقايسه

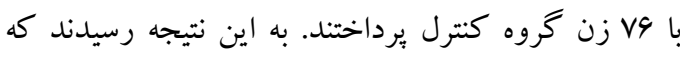

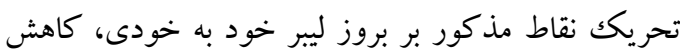
نياز به اينداكشن و كاهش طول مدت ليير (Nץ./P<) مؤثر است( (Y). در مطالعه Deepak و همكاران (rا. (Y) كه به بررسى اثر طب فشارى نقاط كيسه صفراى آ؟، نقاط دست، نقاط קֶت، SP6، نقاط •9 مثانهاى و نقاط ال كليه روى شدت و مدت ليبر در مرحله اول زايمان در .9 نفر از زنان

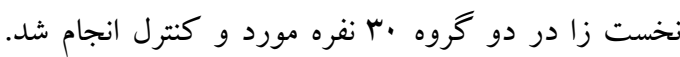
1/49/V

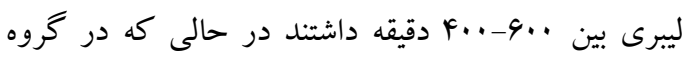
كنترل فقط ·ل درصد افراد در اين دامنه قرار داشتند. از

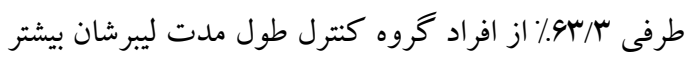

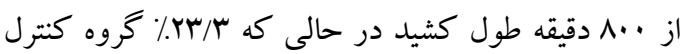
در اين ميزان قرار داشتند. مدت زمان مرحله اول زايمان در دو گروه تفاوت آمارى معنىدارى را نشان داد

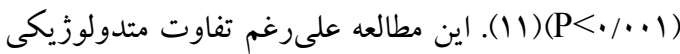
كه با مطالعه ما داشت مشخص نمود طب فشارى مىتواند

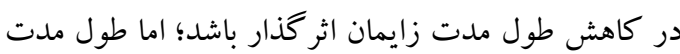
مرحله اول زايمان در مطالعه Deepak و همكاران (rا.r) در محدوده بالاى .F ع دقيقه قرار دارد در حالى كه در مطالعه ما در محدوده ..r-...r دقيقه بود. البته Deepak و همكاران (rا •r) از r بار مداخله ·r دقيقهاى بهره جستند. در حالى كه در مطالعه ما، سه مرحله مداخله ·r دقيقهاى 
44 براسى تاثير طب فشارى...

مكمل مىتواند با افزايش رهايى اندروفين همراه باشد(YN-

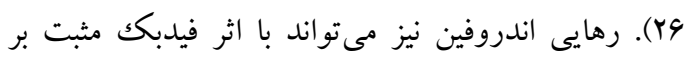
رهاشدن اكسى توسين از غده هييوفيز اثر گذار باشد كه به طور مستقيم بر انقباضات رحمى مؤثر است(19). شايد دليل نياز بيشتر به اكسى توسين در گروه كنترل و طب فشارى نا به جا به اين دليل ايجاد شد. جنانجه بر طبق مطالعه ما فشار بر نقطه كيسه صفراوى بـ منجر به كاهش نياز به استفاده از اكسى توسين كردد، به نظر

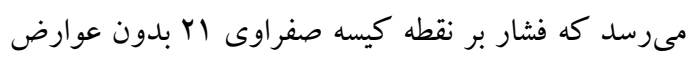
مادرى و جنينى همراه است. جرا كه منجر به ترشح اكسى به له

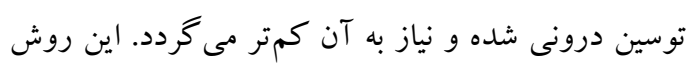
مىتواند با تأثير بر شروع و كاهش طول مدت زايمان در

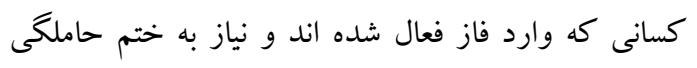
دارند، مؤثر باشد. نتايج مطالعه حاضر نشان داد تفاوتى بين سه گرووه از نظر ييامد باردارى، عوارض مادرى و نوزادى (نوع زايمان و نمره آيگار) وجود ندارد. در مطالعه Akbarzadeh و و

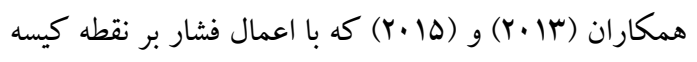
صفراوى الY بود، به كار بردن اين روش بر روى نمره آيگار تأثيرى نداشت(Yq, YY). در مطالعه Soltani.

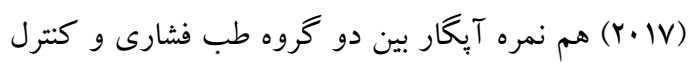
تفاوت نداشت(·r). در مطالعه Mehri و همكاران (Y) (Y) تفاوت بين نمره آيگار در دو گرووه مداخله با طب فشارى و كنترل وجود نداشت همجينين ميزان رضايت مندى از زايمان با استفاده از طب فشارى در گرووه مداخله بيشتر از گروه كنترل بود كه با نتايج مطالعه حاضر همسو است( است). از آنجايى كه حمايت روانى مادر در جهت كاهش درد و در نتيجه تأثير آن بر طول مدت زايمان مهم است، لذا محقق با رفتارى يكسان بر بالين تمام مادران در هر سه كروه حضور يافته است و كليه مراقبتهاى روتين را انجام داد كه به بمان

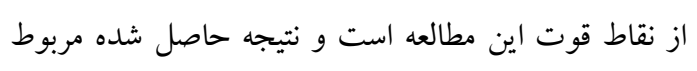
به تأثير طب فشارى است. نقطه قوت ديخر اين مطالعه استفاده از گروه نا به جا در مطالعه جهت بروسى اثر اثر
كه بر طبق مطالعه Akbarzadeh و همكاران (ها +Y)انجام طب فشارى در دو مرحله با كاهش بيشترى در طول مدت زايمان همراه است، در مطالعه حاضر در جهت رفع اين نقيصه اعمال فشار در سه مرحله ديلاتاسيونى تكرار شد. اين مطالعه نشان داد تكرار تحريكك مى تواند مؤثر باشد. شايد دليل تفاوت ظريفى كه در نتايج مطالعه ما و Akbarzadeh

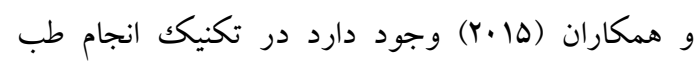
فشارى، روشهاى اندازه گيرى و تفاوت در طول مدت فاز نهفته در دو گروه باشد. همان طور كه انتظار مى رود طول

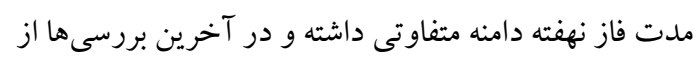
ديلاتاسيون 9 سانتىمتر آغاز فاز فعال زايمان در نظر كرفته

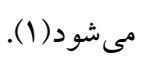
در طب سنتى جين اين عقيده وجود دارد كه بيمارى در نتيجه عدم تعادل انرزى ايجاد مى شود، براى تصحيح اين اين

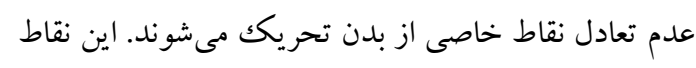
در طول مريدينها قرار دارد كه در سرتاسر بدن براى اركانهاى بدن انرزى رسانى مى كنند. لازم نيست كه اين

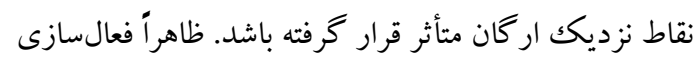
اين نقاط موجب آزادسازى انرزى مى گردد. طب فشارى، يكى از شاخههاى علوم يزشكى جامعه نگر بوده و در واقع يكى ازدرمانهاى طب مكمل است. اين طب معتقد است

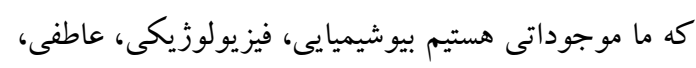

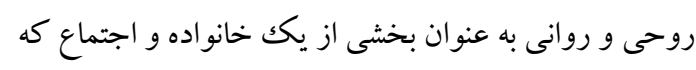

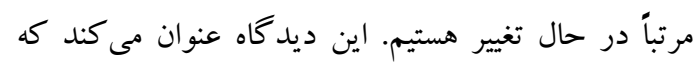
سلامتى و بيمارى به حفظ همه اين فعلوانفعالات و روابط

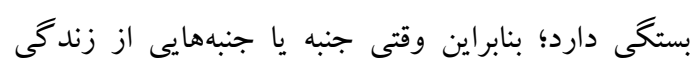
دجار آشفتگى مىشود، ساير ابعاد هم ممكن است از اين

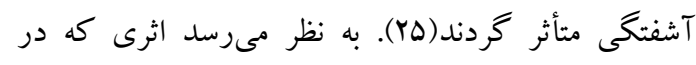
مطالعه فوق به آن دست يافتيم متأثر از اين ديدكاه باشد. در مطالعات مختلف آشكار شد زنان در طى ليبر استرس و اضطراب را تجربه مى كنند و مطالعات نشان داده تجربه استرس با افزايش ميزان كاته كول آمين ها و كاهش اندروفين ها همراه است. در حالى كه روش هاى طب مبرسي 


$$
\begin{aligned}
& \text { 4V كيتى ازازلى } \\
& \text { اعمال فشار بر نقطه كيسه صفراوى اY بر طول مدت ليبر } \\
& \text { يّاسبويى اين نقطه است. در اين مطالعه با توجه به اينكه } \\
& \text { اثر كذار نبود؛ اما ميزان نياز به اكسىتوسين را كاهش دئه داد. }
\end{aligned}
$$

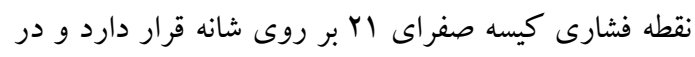

$$
\begin{aligned}
& \text { طب فشارى نقطه كيسه صفراى اY به عنوان يكك تكنيك آك }
\end{aligned}
$$

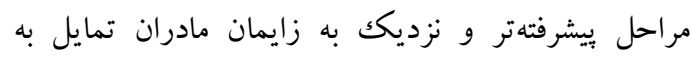

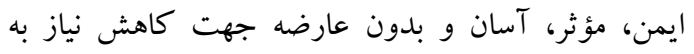

$$
\begin{aligned}
& \text { خوابيدن به بهلو به دنبال تشديد دردهاى زايمانى را دارند، } \\
& \text { مصرف اكسى توسين است. } \\
& \text { فشار بيشتر بر روى يكى از شانهها انجام شد. در نتيجه }
\end{aligned}
$$

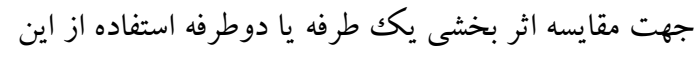

$$
\begin{aligned}
& \text { تشكر و قدردانى } \\
& \text { اين مقاله طرح تحقيقاتى مصوب دانشگاه علوم يزشكى }
\end{aligned}
$$

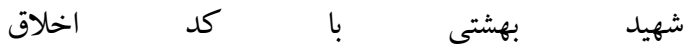

$$
\begin{aligned}
& \text { IR.SBMU.PHNM.1395.705 مىباشد. از معاونت } \\
& \text { محترم يزووهشى دانشگاه علوم يزشكى شهيد بهشتى تهران، } \\
& \text { مسئولين بيمارستان شهيد مفتح ورامين و مادرانى كه انجام } \\
& \text { اين تحقيق را ممكن ساختند تشكر مى شود. } \\
& \text { نقطه فشارى نيازمند به مطالعات بيشترى است. همجنين } \\
& \text { ييشنهاد مى شود جهت تعيين اثربخشى دقيق تر در مطالعات }
\end{aligned}
$$

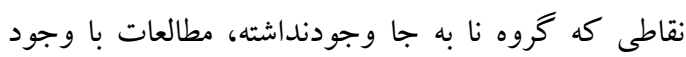

$$
\begin{aligned}
& \text { كروه نا به جا وكروه كنترل، تكرار شود. } \\
& \text { نتيجه كيرى } \\
& \text { منابc }
\end{aligned}
$$

1.Dashe JS. Bloom SL. Spong CY. Hoffman BL. Williams Obstetrics. McGraw Hill Professional, 2018.

2.Macdonald S. Johnson G. Mayes' Midwifery E-Book. Elsevier Health Sciences, 2017.

Macdonald S, Johnson G. Mayes' Midwifery E-Book: Elsevier Health Sciences; 2017.

3.Lowdermilk DL, Perry SE, Cashion MC, Alden KR, Olshansky E. Maternity and Women's Health Care E-Book: Elsevier Health Sciences; 2019.

4.London ML, Ladewig PW, Davidson M, Ball JW, Bindler RC, Cowen K. Maternal \& child nursing care. 5 ed: Pearson; 2016.

5.Kahnamoyiagdam F, Rostamnejad M, Aghamohammadi M. The effect of castor oil on the induction of labor: a clinical trial. J Urmia Nurs Midwifery Fac. 2014;12(5):348-53.

6.Fraser M. Cooper MA. Myles text book for midwives. Midwifery. 2003;33(3):752.

7.Topraghlou SB, Shafaie FS, Mirghafourvand M, Salehi N.Comparing the Effects of Acupressure at the Hugo Point and Hyoscine on the Duration of Labor Stages and Fetalneonatal Outcomes in Nulliparous Women: A Controlled Randomized Clinical Trial. IJWHR, 2009; 7(3):393-399.

8.Fraser WD, Cayer M, Soeder BM, Turcot L, Marcoux S, Group PS .Risk factors for difficult delivery in nulliparas with epidural analgesia in second stage of labor. Obstetrics \& Gynecology. 2002;99(3):409-18.

9.Queenan JT. Spong CY. Lockwood CJ. Queenan's management of high-risk pregnancy: an evidence-based approach. John Wiley \& Sons, 2012.

10.World Health Organization (WHO) recommendations: intrapartum care for a positive childbirth experience: World Health Organization; 2018.

11.Deepak A, Chopra S. Effect of acupressure on intensity of labor pains and duration of first stage of labor among primigravida mothers. Iran J Nurs Midwifery Res. 2013; 9(4):178-186. 12.Koh LM, Percival B, Pauley T, Pathak S. Complementary therapy and alternative medicine: effects on induction of labour and pregnancy outcome in low risk post-dates women. Heliyon. 2019;5(11):e02787. 
4.... براسى تاثير طب فشان

13.Mollart LJ, Adam J, Foureur M. Impact of acupressure on onset of labour and labour duration: A systematic review. WOMEN BIRTH. 2015;28(3):199-206.

14.Ozgoli G, Mobarakabadi SS, Heshmat R, Majd HA, Sheikhan Z. Effect of LI4 and BL32 acupressure on labor pain and delivery outcome in the first stage of labor in primiparous women: a randomized controlled trial. Complement Ther Med. 2016;29:175-80.

15.Xinnong C. Chinese acupuncture and moxibustion: Foreign Languages Press. Beijing; 1987:513-23.

16Pillitteri A. Maternal \& child health nursing: care of the childbearing \& childrearing family. Lippincott Williams \& Wilkins; 2010.

17.Lowdermilk Dl. Perry S. Maternity nursing. St. Louis: Mosby. 2003.

18.Betts D. Deadman P. Heese I. The essential guide to acupuncture in pregnancy \& childbirth. Chin. Med. 2006;17(3):16-19.

19.Chang SB, Park YW, Cho JS, Lee MK, Lee BC, Lee SJ. Differences of cesarean section rates according to San-Yin-Jiao (SP6) acupressure for women in labor. j korean acad nurs. 2004;34(2):324-32.

20.Kazemi F, Alimoradi Z, Valiani M, Gorji M. Comparing Effect of Auricular Acupressure and Body Acupressure on Pain and Duration of First Stage of Labor: Study Protocol for a Randomized Controlled Trial. Europepmc.org.2019. DOI: 10.21203/rs.1.20/v4

21.Ingram J, Domagala C, Yates S. The effects of shiatsu on post-term pregnancy. Complement Ther Med. 2005;13(1):11-5.

22AKkbarzadeh Marzieh, Moradi Zahra, Zrae Najaf, Hadianfard Mohammad Javad, Azam J. Comparison of the effect of one-step massage of SP6 and GB21 on the length of stages and type of delivery in nulliparous women referred to selected hospitals of Shiraz University of Medical Sciences: randomized clinical trial. Qom Univ Med Sci J. 2013;7(3):54-61.

23.Saghaei M. Random allocation software for parallel group randomized trials. BMC Med. Res. Methodol. 2004;4(1):26.

24.Akbarzadeh M, Moradi Z, Jowkar A, Zare N, Hadianfard MJ. Comparing the effects of acupressure at the Jian Jing-Gall Bladder Meridian (GB-21) point on the severity of labor pain, duration and cesarean rate in mono-and bi-stage interventions. Women's Health Bulletin. 2015;2(1):e32128.

25.Ghasemi AN. Soleimani k. Traditional and new medical approach. Tehran: Teymorzadeh; 2003.[Persian].

26.Lederman RP, Lederman E, McCann DS. Anxiety and epinephrine in multiparous women in labor: relationship to duration of labor and fetal heart rate pattern. Am J Obstet Gynecol. 1985;153(8):870-7.

27.Mirzaei F, Keshtgar S, Kaviani M, Rajaeifard A. The effect of lavender essence smelling during labor on cortisol and serotonin plasma levels and anxiety reduction in nulliparous women. Journal of Kerman University of Medical Sciences. J Kerman Univ Med Sci. 2009; 16(3):245-54.

28.Zachariah R. Social support, life stress, and anxiety as predictors of pregnancy complications in low income women. Res Nurs Health. 2009;32(4):391-404.

29.AKkbarzadeh Marzieh, Moradi Zahra, Zrae Najaf, Hadianfard Mohammad Javad, Azam j. Comparison of the effect of one-step massage of SP6 and GB21 on the length of stages and type of delivery in nulliparous women referred to selected hospitals of Shiraz University of Medical Sciences: randomized clinical trial. Qom Univ Med Sci J. 2013;7(3):54-61.

30.Soltani M, Azhari S,Khorsand Vakilzadeh A, Tara F, Mazloum SR. The effect of acupressure on uterine tone and pain after delivery. Iran. J. Obstet. Gynecol. Infertil. 2017;20(9):91-100. 
49 كيتى ازتكلى

31.Mehri Z, Moafi F, Mafi M, Habibi M, Ranjkesh F. Effects of Acupressure on Labor Length and Outcome in Nulliparous Women: A Clinical Trial. J Qazvin Univ Med Sci. 2019;23(2):116-27. 